\title{
Häberlein, Mark, Kuhn, Christian, Fremde Sprachen in frühneuzeitlichen Städten. Lernende, Lehrende und Lehrwerke
}

Benoît Grévin

\section{(2) OpenEdition}

Édition électronique

URL : http://journals.openedition.org/ifha/6496

DOI : $10.4000 /$ ifha.6496

ISSN : 2198-8943

Éditeur

IFRA - Institut franco-allemand (sciences historiques et sociales)

Référence électronique

Benoît Grévin, « Häberlein, Mark, Kuhn, Christian, Fremde Sprachen in frühneuzeitlichen Städten Lernende, Lehrende und Lehrwerke », Revue de I'IFHA [En ligne], Date de recension, mis en ligne le 01 janvier 2012, consulté le 22 septembre 2020. URL : http://journals.openedition.org/ifha/6496 ; DOI https://doi.org/10.4000/ifha.6496

Ce document a été généré automatiquement le 22 septembre 2020.

(CIFHA 


\title{
Häberlein, Mark, Kuhn, Christian, Fremde Sprachen in frühneuzeitlichen Städten. Lernende, Lehrende und Lehrwerke
}

\author{
Benoît Grévin
}

1 Cet ouvrage collectif, réunissant les actes d'un colloque tenu à l'université de Bamberg en juin 2007, concerne un sujet bien plus restreint que son titre ne le laisse entendre. Il eût en effet été plus correct de l'intituler Fremde Sprachen in frühneuzeitlichen Städten Süddeutschlands ..., car il réunit un ensemble de quatorze contributions concernant essentiellement les méthodes d'acquisition de langues étrangères (latin et grec généralement exceptés) par le patriciat urbain et les milieux commerçants de Nuremberg et Augsbourg (p. 23-176 et 197-226) à l'époque moderne. Les trois exceptions concernent respectivement l'utilisation de mots d'origine ibérique dans le milieu des commerçants de Ravensburg à la fin du Moyen Âge (p. 177-196), l'importance de l'acquisition des langues étrangères dans les stratégies familiales du patriciat suisse allemand à l'orée du XIXe siècle (p. 249-264, cf. infra pour la minceur du propos), et l'enseignement du français et de l'anglais à Lüneburg à l'époque moderne (227-248). Il s'agit donc, à ces exceptions près, de réunir un faisceau d'études sur les stratégies d'acquisition des langues étrangères modernes dans les milieux marchands et patriciens d'Augsbourg et Nuremberg, essentiellement aux XVIe et XVIIe siècles. Cette restriction donne une grande cohérence à l'ouvrage, en permettant de multiplier les angles d'attaque, et d'examiner à la fois la question du point de vue des apprenants et de leurs motivations, des langues et des aires d'attraction, des enseignants et des méthodes employées, conformément à la problématique indiquée en sous-titre. Le contenu des communications reflète l'importance de l'apprentissage de l'italien et du français (le poids relatif du premier s'effaçant au cours de l'époque moderne au profit du second), et le glissement dans un milieu marchand qui tend à se conformer aux idéaux de la noblesse de stratégies d'apprentissage majoritairement mercantiles vers une conception de la langue étrangère comme instrument de représentation sociale. Se 
dessine un arc d'apprentissage lié aux réseaux commerciaux qui privilégie l'Italie du Nord et la Toscane (Venise, Gêne, Florence, Sienne ...) et, pour l'aire francophone, les pays de confins (Pays-Bas francophones, Lyonnais), Paris et le centre (Tours, Poitiers). La communication d'A. Kermer (p. 177) donne quelques lumières sur l'impact de commerces plus lointains (Catalogne et Valence), celle de H. Klatte (p. 197) sur les conséquences linguistiques des relations avec la Bohême et Prague. De manière contrastive, puisque concernant une ville de l'Allemagne du Nord (Lüneburg), l'article de K. Schröder donne également une idée des voies de pénétration de l'anglais dans l'espace germanique au XVIIIe siècle. Si certaines communications font tache par leur caractère anecdotique (P. Cimino, p. 249, qui fait passer le récit de deux itinéraires individuels dont l'un pour le moins exceptionnel pour les bases d'une réflexion sociolinguistique en fait absente), l'ensemble de l'ouvrage, à condition de garder en mémoire la problématique choisie, qui exclut toute réflexion sur les usages de ces langues dans la société allemande, contient nombre d'informations (notamment sur les carrières des enseignants d'origine étrangère) sur le problème de l'enseignement des langues étrangères dans cet espace urbain de l'Allemagne du Sud moderne. 